\title{
pH do Exsudato na Avaliação da Viabilidade de Sementes de Araucaria angustifolia
}

\author{
Cristhyane Garcia Araldi, Cileide Maria Medeiros Coelho²
}

${ }^{1}$ Departamento de Fitotecnia, Universidade Federal de Santa Catarina - UFSC, Florianópolis/SC, Brasil

${ }^{2}$ Departamento de Agronomia, Universidade do Estado de Santa Catarina - UDESC, Lages/SC, Brasil

\begin{abstract}
RESUMO
Este estudo objetivou verificar a eficiência de métodos de pré-condicionamento e períodos de embebição em água para a realização do teste de $\mathrm{pH}$ do exsudato para avaliação da viabilidade de sementes de Araucaria angustifolia. Testaram-se três pré-condicionamentos (semente inteira; semente seccionada longitudinalmente; embrião excisado) e três períodos de embebição em água (30, 60 e 90 minutos), avaliando-se a coloração da solução. Adicionalmente, as sementes foram envelhecidas artificialmente por 4 e 8 dias, a $40^{\circ} \mathrm{C}$. A viabilidade foi superior em embriões excisados e embebidos por 30 minutos, apresentando elevado coeficiente de correlação com os testes de germinação e tetrazólio. Para sementes em avançado estádio de deterioração, a avaliação deve associar a coloração da solução ao aspecto dos tecidos. Conclui-se que o teste do $\mathrm{pH}$ do exsudato é eficiente na avaliação da viabilidade de sementes de A. angustifolia, devendo ser realizado utilizando-se apenas o embrião embebido em água por 30 minutos.
\end{abstract}

Palavras-chave: germinação, qualidade fisiológica, sementes florestais.

\section{pH Exudate Test for Determining the Viability of Araucaria angustifolia Seeds}

\begin{abstract}
This study aimed to verify the efficiency of methods of pre-conditioning and periods of water immersion to perform the $\mathrm{pH}$ exudate test to evaluate the viability of Araucaria angustifolia seeds. Three pre-conditioning methods (whole seed, seed longitudinally sectioned, excised embryo) and three water imbibition periods (30,60 and 90 minutes) were tested, and the solution color was evaluated. Additionally, the seeds were artificially aged for four and eight days at $40{ }^{\circ} \mathrm{C}$. The viability was higher in embryos excised, after 30 minutes of imbibition, showing high coefficient of correlation with the germination and tetrazolium tests. Seeds at advanced stage of deterioration should be evaluated by associating the solution color with the tissue aspect. In conclusion, the $\mathrm{pH}$ exudate test is efficient to evaluate the viability of A. angustifolia seeds, and it should be performed using excised embryo imbibed in water for 30 minutes.
\end{abstract}

Keywords: germination, physiological quality, forest seeds. 


\section{INTRODUÇÃO}

A espécie Araucaria angustifolia (Bert) O. Ktze. é a única do gênero nativa do Brasil, com grande relevância ecológica, econômica e social na sua região de ocorrência natural (Schlögl et al., 2007). Por isso, diversos esforços têm sido conduzidos a fim de propagar e conservar a espécie (Balbuena et al., 2011). $\mathrm{Na}$ avaliação da qualidade fisiológica de sementes, o teste de germinação é amplamente utilizado para a maioria das espécies. Entretanto, as sementes de A. angustifolia, as quais constituem sua principal forma de propagação, apresentam germinação lenta e perdem rapidamente a viabilidade após a colheita (Garcia et al., 2014).

$O$ período de permanência das sementes de A. angustifolia em teste de germinação pode chegar a 70 dias, quando há a máxima formação de plântulas normais (Garcia et al., 2014; Shibata et al., 2013). Em sementes que apresentam germinação lenta e desuniforme, os resultados do teste de germinação podem não refletir a real condição fisiológica das sementes, acentuando a predisposição ao ataque de patógenos durante o período de execução do teste, prejudicando seriamente os resultados obtidos pela germinação (Carvalho et al., 2002; Hilst et al., 2012).

A rapidez na obtenção de resultados confiáveis é um dos principais aspectos considerados na avaliação da qualidade das sementes, pois permite a agilidade na tomada de decisões, possibilita seu emprego em escalas mais amplas, diminuindo os riscos e custos em operações como colheita, processamento, armazenamento e comercialização (Reis et al., 2010; Barbieri et al., 2012; Hilst et al., 2012). Por isso, torna-se interessante o uso de testes rápidos para a avaliação da viabilidade das sementes de A. angustifolia, uma vez que permitem a expressão da qualidade fisiológica com maior precisão em determinado período de tempo.

Alguns testes rápidos de avaliação da qualidade fisiológica vêm sendo aplicados com eficiência em sementes de A. angustifolia, como a condutividade elétrica (Medeiros \& Abreu, 2007; Garcia et al., 2014) e o teste de tetrazólio (Oliveira et al., 2014), sendo esse indicado pelas Regras para Análise de Sementes - RAS (Brasil, 2009). Não há relatos do uso do teste de $\mathrm{pH}$ do exsudato em sementes de A. angustifolia, mas acredita-se que sua aplicação pode ser uma boa alternativa, pois tem sido utilizado com sucesso para sementes de outras espécies como soja (Amaral \& Peske, 1984; Tozzo \& Peske, 2008), feijão (Fernandes et al., 1987), milho (Cabrera \& Peske, 2002), ervilha (Rech et al., 1999), trigo (Amaral \& Peske, 2000) e citros (Carvalho et al., 2002), além da espécie florestal copaíba (Matos et al., 2009).

A avaliação da viabilidade pelo teste do $\mathrm{pH}$ do exsudato possui baixo custo se comparada ao teste de tetrazólio, apresenta rapidez na obtenção de resultados e facilidade de execução, evita a utilização e/ou armazenamento desnecessário de lotes com baixo vigor, tornando a técnica promissora (Amaral \& Peske, 2000; Ramos et al., 2012). No entanto, alguns autores destacam a importância do desenvolvimento e/ou ajuste de metodologia desses testes rápidos para as diferentes espécies, já que deles dependerá a eficiência dos procedimentos na avaliação do potencial fisiológico das sementes (Lopes et al., 2013).

O teste do $\mathrm{pH}$ do exsudato é baseado na permeabilidade das membranas, envolvendo a lixiviação de solutos e a integridade do tegumento (Santos et al., 2011). Durante a embebição das sementes em água, ocorre a liberação de metabólitos como açúcares, ácidos orgânicos e íons $\mathrm{H}^{+}$, os quais acidificam o meio e provocam a diminuição do $\mathrm{pH}$ do exsudato das sementes (Rech et al., 1999; Carvalho et al., 2002). Por isso, enquanto as sementes com elevada qualidade fisiológica apresentam baixa lixiviação de solutos e não promovem grandes alterações no $\mathrm{pH}$ do meio, as sementes deterioradas liberam maior quantidade de íons, resultando em menores valores de $\mathrm{pH}$.

Nesse sentido, o objetivo desta pesquisa foi avaliar o potencial de uso do teste de $\mathrm{pH}$ do exsudato na avaliação da viabilidade de sementes de A. angustifolia, visando obter um método de pré-condicionamento e um período de embebição em água, como formas de reforçar as metodologias já disponíveis de avaliação da qualidade fisiológica das sementes da espécie.

\section{MATERIAL E MÉTODOS}

As sementes de A. angustifolia foram coletadas em maio de 2012, a partir de duas populações localizadas no planalto sul de Santa Catarina, num total de cinco matrizes por população, sendo denominadas lote 1 (provenientes de Lages, localidade de Lambedor) e lote 2 (provenientes de São José do Cerrito). Após homogeneização manual 
das sementes de cada lote, as amostras foram separadas em quatro repetições e avaliadas quanto ao grau de umidade, viabilidade, através do teste de germinação, tetrazólio e pH do exsudato, e vigor, através do cálculo do índice de velocidade de germinação e teor de matéria seca da plântula.

O grau de umidade foi determinado a partir de três sementes por repetição, cortadas transversalmente, as quais foram pesadas e levadas à estufa a $105 \pm 3{ }^{\circ} \mathrm{C}$, por 24 horas (Brasil, 2009).

O teste de germinação foi conduzido utilizando-se 25 sementes por repetição, previamente tratadas com solução de hipoclorito de sódio a $2 \%$, por três minutos. Utilizaram-se bandejas plásticas contendo areia autoclavada como substrato, a qual foi umedecida até cerca de $60 \%$ da capacidade máxima de retenção de água (Brasil, 2009), monitorando-se a quantidade de água durante o período de duração do teste. O teste foi realizado em germinadores do tipo Mangelsdorf, com fotoperíodo de 12 horas e temperatura constante de $25 \pm 1^{\circ} \mathrm{C}$. As avaliações de plântulas normais foram realizadas a cada três dias para o cálculo do índice de velocidade de germinação (IVG) até o período de 64 dias após o início do teste de germinação, respeitando-se a expressão do máximo potencial germinativo das sementes. Os períodos de 60 e 70 dias após o início do teste de germinação foram considerados por outros autores para a análise dos resultados de plântulas normais em sementes de A. angustifolia, quando há a máxima germinação (Moreira-Souza \& Cardoso, 2003; Garcia et al., 2014, respectivamente). O critério para avaliação de plântulas normais foi adotado conforme prescrito nas RAS (Brasil, 2009). O IVG foi calculado conforme a fórmula proposta por Maguire (1962). Visando identificar diferentes desempenhos iniciais das plântulas em função do lote, determinou-se o teor de matéria seca das plântulas normais, obtido através da secagem em estufa a $80{ }^{\circ} \mathrm{C}$ por 24 horas (Krzyzanowski et al., 1999).

O teste de tetrazólio foi realizado conforme metodologia de Brasil (2009) com adaptações de Oliveira et al. (2014). Foram utilizados 25 embriões por repetição, os quais foram imersos em solução de 2, 3 , 5 trifenil-cloreto de tetrazólio a $0,1 \%$ e permaneceram no escuro por uma hora a $25^{\circ} \mathrm{C}$. Os embriões foram classificados em viáveis ou inviáveis de acordo com a coloração e aspecto dos tecidos, extensão e localização dos danos em relação às áreas essenciais ao crescimento.

A eficiência do teste do $\mathrm{pH}$ do exsudato em sementes de A. angustifolia através da metodologia de análise individual foi realizada em duas etapas. A primeira consistiu em avaliar a viabilidade de 25 sementes por repetição, provenientes dos lotes 1 e 2, testando-se três pré-condicionamentos: I - semente inteira sem o tegumento; II - semente sem o tegumento e seccionada longitudinalmente na região do embrião; III - embrião excisado. As sementes foram embebidas individualmente em $5 \mathrm{~mL}$ de água destilada, $\mathrm{pH}$ de 8,35, a $25^{\circ} \mathrm{C}$. Após 30, 60 e 90 minutos de embebição, foram avaliados o pH das soluções de embebição, com uso de peagâmetro, e a coloração das soluções imediatamente após a adição de duas gotas de uma solução de carbonato de sódio $(8 \mathrm{~g} / \mathrm{L})$ e fenolftaleína (5\%) dissolvidos em água destilada e fervida.

Para se avaliar a eficiência do teste do $\mathrm{pH}$ do exsudato nas alterações de viabilidade de sementes em processo de deterioração realizou-se uma segunda etapa, a qual consistiu em submeter 25 sementes por repetição, provenientes do lote 1 , ao envelhecimento artificial. $\mathrm{O}$ envelhecimento foi realizado por períodos de 4 e 8 dias, sob temperatura de $40 \pm 1^{\circ} \mathrm{C}$, em câmara germinativa BOD, utilizando-se tela de aço em caixas plásticas tipo gerbox vedadas, contendo $40 \mathrm{~mL}$ de água destilada (sem contato com as sementes) para manter elevada a umidade relativa do ar (Garcia et al., 2014). Após finalizados os períodos de envelhecimento, as sementes foram submetidas aos testes de grau de umidade, germinação, IVG, teor de matéria seca e tetrazólio, conforme descritos anteriormente, e ao teste do $\mathrm{pH}$ do exsudato com o pré-condicionamento III (embrião excisado) e com 30 minutos de embebição em água, pois esse método permitiu identificar o maior percentual de sementes viáveis na primeira etapa do experimento.

$\mathrm{O}$ experimento foi realizado em delineamento inteiramente casualizado. Para os resultados obtidos na primeira etapa do teste do $\mathrm{pH}$ do exsudato, utilizou-se esquema trifatorial (dois lotes $\times$ três pré-condicionamentos $\times$ três períodos de embebição). Os dados obtidos em percentagem foram transformados em arco seno $\sqrt{ } \%$, submetidos à análise de variância, sendo as médias comparadas pelo teste de Tukey a $5 \%$ de significância através do programa estatístico SAS (SAS, 2009). Os resultados do teste do $\mathrm{pH}$ do 
exsudato foram relacionados com os dados dos testes de germinação e tetrazólio, através da obtenção dos coeficientes de correlação e regressão linear simples entre as porcentagens de sementes viáveis, obtidas pelo $\mathrm{pH}$ do exsudato, e as porcentagens de viabilidade, obtidas pelos testes de germinação e tetrazólio.

\section{RESULTADOS E DISCUSSÃO}

A aplicação da solução indicadora (carbonato de sódio e fenolftaleína) após a embebição das sementes em água permitiu agrupá-las em quatro categorias de coloração, sendo: 1) rosa forte; 2) rosa médio; 3) rosa fraco; 4) incolor. As sementes cujas soluções de embebição apresentaram coloração rosa forte e rosa médio foram consideradas viáveis e aquelas cuja solução apresentou coloração rosa fraco ou incolor foram consideradas inviáveis, conforme recomendação de Amaral \& Peske (1984).

A solução indicadora apresentou pH de 10,53 sob temperatura de $25^{\circ} \mathrm{C}$. Após a embebição das sementes em água e a adição de duas gotas da solução indicadora, os dados de pH obtidos variaram de 7,82, para soluções incolores, a valores superiores a 9,50, para soluções de coloração rosa forte. Esses resultados estão de acordo com o relatado por outros autores, os quais indicam que as sementes mais deterioradas tendem a apresentar maior lixiviação de solutos durante a embebição e, portanto, exsudatos com maior poder tamponante, refletindo-se em soluções incolores (Amaral \& Peske, 1984; Rech et al., 1999).

Os resultados indicaram que o $\mathrm{pH}$ da solução de embebição para os pré-condicionamentos I (semente inteira sem o tegumento) e II (semente sem o tegumento e seccionada longitudinalmente) não se altera, ou sofre pequena alteração após a adição da solução indicadora, sem que haja alteração na coloração do exsudato (Tabela 1). No entanto, a utilização dos embriões excisados permitiu identificar um elevado número de sementes viáveis. Embora não tenha sido observada alteração na coloração das soluções de embebição, quando foram utilizados os pré-condicionamentos I e II não foi possível afirmar que as sementes estavam inviáveis ou pouco viáveis. Cabe destacar que a avaliação individual das sementes é importante, considerando que há variações na qualidade de sementes de um mesmo lote, pois as sementes não atingem a maturidade fisiológica e, portanto, a máxima qualidade, simultaneamente (Muasya et al., 2006), com reflexos na viabilidade pós-colheita.

Não foram observadas diferenças significativas $(\mathrm{p}<0,05)$ na qualidade fisiológica dos lotes em relação aos pré-condicionamentos, ou seja, a metodologia utilizando embriões excisados resultou em maiores valores de viabilidade para ambos os lotes. Por isso, optou-se por apresentar na Tabela 1 apenas a comparação entre as médias de viabilidade dos embriões excisados (pré-condicionamento III) dos dois lotes em relação aos períodos de embebição.

Tabela 1. Percentual de sementes viáveis de A. angustifolia obtido pelo teste do $\mathrm{pH}$ do exsudato realizado em sementes inteiras sem o tegumento, sementes sem o tegumento e seccionadas longitudinalmente e embrião excisado, após três períodos de embebição em água (30, 60 e 90 minutos) a $25^{\circ} \mathrm{C}$.

Table 1. Percentage of $A$. angustifolia viable seeds obtained by $\mathrm{pH}$ exudate test, conducted in whole seeds without tegument, seeds without tegument and longitudinally sectioned, and excised embryo, after three periods of water imbibition (30, 60 and 90 minutes) at $25^{\circ} \mathrm{C}$.

\begin{tabular}{ccccc} 
& & \multicolumn{3}{c}{ Período de embebição (minutos) } \\
\cline { 2 - 5 } & Pré-condicionamento & $\mathbf{3 0}$ & $\mathbf{6 0}$ & $\mathbf{9 0}$ \\
\multirow{2}{*}{ Lote 1} & Sem tegumento & 0 & 0 & 0 \\
& Secção longitudinal & 0 & 4 & 0 \\
\multirow{2}{*}{ Lote 2} & Embrião & $90 \mathrm{Aa}$ & $84 \mathrm{Ba}$ & 0 \\
& Sem tegumento & 0 & 0 & 0 \\
Secção longitudinal & Embrião & 0 & 0 & $88 \mathrm{Aa}$ \\
\hline
\end{tabular}

As letras referem-se ao teste de Tukey $(\mathrm{p}<0,05)$ e comparam: na linha, os períodos de embebição (maiúsculas); na coluna, os lotes (minúsculas). 
Os resultados demonstram que o percentual de embriões viáveis é dependente do período de embebição e, portanto, o ajuste desse período é fundamental para estimar a viabilidade de um lote de sementes de A. angustifolia. Para a espécie em estudo, o período de 30 minutos de embebição permitiu identificar maior número de sementes viáveis em relação aos demais períodos para ambos os lotes, concordando com o que foi observado para outras espécies, como soja (Amaral \& Peske, 1984), ervilha (Rech et al., 1999) e citros (Carvalho et al., 2002). Esse período de embebição agiliza a obtenção de resultados e, além disso, por não ser um método destrutivo, os mesmos embriões seccionados avaliados pelo teste do $\mathrm{pH}$ do exsudato podem ser utilizados para o teste de tetrazólio, reduzindo o tempo de preparo para a avaliação da viabilidade.

Foi sugerido que os valores de $\mathrm{pH}$ podem variar com a qualidade e o pH inicial da água utilizada, a temperatura, a duração do período de embebição e a umidade inicial das sementes (Amaral \& Peske, 1984). Não foi observada diferença significativa entre o grau de umidade inicial das sementes de A. angustifolia dos lotes $1(53 \%)$ e 2 (54\%) (Tabela 2). Além disso, não foram detectadas diferenças significativas $(\mathrm{p}<0,05)$ entre os lotes quanto à viabilidade observada pelo teste de germinação ( $95 \%$ - lote 1 e $98 \%$ - lote 2) e tetrazólio ( $92 \%$ - lote 1 e $96 \%$ - lote 2), IVG (0,75 - lote 1 e 0,74 - lote 2$)$, e matéria seca das plântulas (5,1 mg.plântula ${ }^{-1}$ - lote 1 e 5,0 mg.plântula ${ }^{-1}$ - lote 2$)$, como pode ser observado na Tabela 2.
Diversos são os fatores que podem influenciar na obtenção de resultados em trabalhos baseados na liberação de exsudatos das sementes, entre eles a presença de danos mecânicos, por insetos, e o próprio estádio de deterioração das sementes (Amaral \& Peske, 1984). Por isso, realizou-se a avaliação da viabilidade de sementes submetidas ao envelhecimento artificial para se avaliar a aplicabilidade do método proposto em sementes durante o processo de deterioração. Nesse caso, utilizaram-se apenas sementes provenientes do lote 1 , pois os lotes não diferiram na primeira etapa da validação do método para o uso do teste do $\mathrm{pH}$ do exsudato.

O envelhecimento artificial não promoveu alterações significativas na umidade das sementes (Tabela 2), mas a viabilidade reduziu progressivamente após 4 (74\% pelos testes de germinação e tetrazólio) e 8 (61\% pelo teste de germinação e $62 \%$ pelo teste de tetrazólio) dias de envelhecimento. A redução na viabilidade de sementes de $A$. angustifolia após o envelhecimento artificial, a $40{ }^{\circ} \mathrm{C}$, também foi observada por outros autores, os quais detectaram $65 \%$ de sementes viáveis após 5 dias de envelhecimento (Garcia et al., 2014) e 31\% após 6 dias de envelhecimento (Fontes et al., 2001). Redução significativa do vigor das sementes também foi observada através do IVG após 4 dias $(0,45)$ e 8 dias de envelhecimento $(0,37)$, e também da matéria seca das plântulas após 8 dias de envelhecimento (3,2 mg.plântula $\left.{ }^{-1}\right)$.

Em embriões excisados envelhecidos artificialmente foi possível identificar que algumas estruturas ou parte delas (eixo embrionário e/ou pelo menos $50 \%$ dos

Tabela 2. Valores médios de grau de umidade (U), germinação (G), índice de velocidade de germinação (IVG), massa seca da plântula (MS), tetrazólio (TZ) e pH do exsudato $(\mathrm{pH})$ para os lotes 1 e 2 de sementes de A. angustifolia, antes e após o envelhecimento artificial (EA) das sementes do lote 1.

Table 2. Mean values of moisture content (U), germination (G), germination speed index (IVG), seedling dry mass (MS), tetrazolium (TZ), and $\mathrm{pH}$ exudate $(\mathrm{pH})$ for lots 1 and 2 of $A$. angustifolia seeds, before and after artificial aging (EA) of seeds from lot 1 .

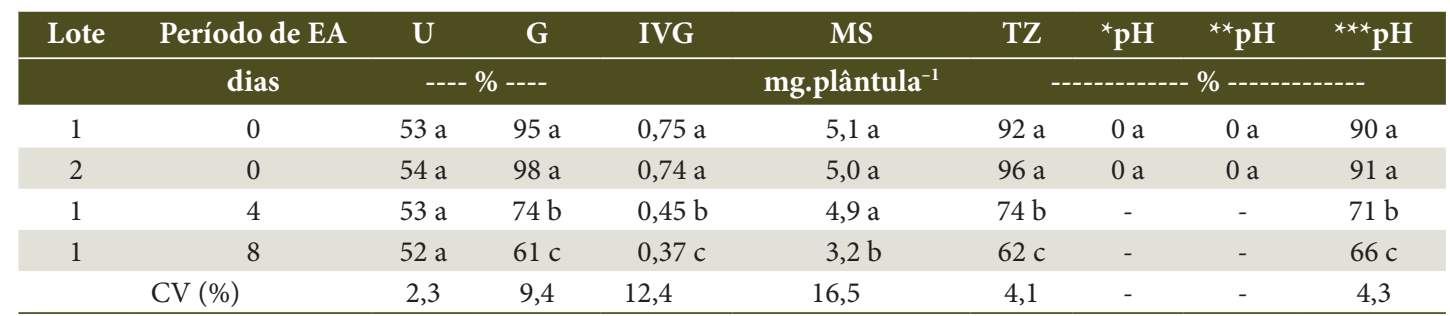

Médias dentro de cada coluna seguidas da mesma letra não diferem entre si pelo teste de Tukey $(\mathrm{p}<0,05)$; os resultados do teste de $\mathrm{pH}$ referem-se aos pré-condicionamentos: ${ }^{*}$ sem tegumento. ${ }^{* *}$ com secção longitudinal. ${ }^{* *}$ somente o embrião, com embebição em água por 30 minutos. 
cotilédones) estavam visualmente deterioradas, escurecidas e/ou com tecidos amolecidos, apesar de terem apresentado solução de embebição com coloração rosa forte durante o teste de $\mathrm{pH}$ do exsudato, com valores de $\mathrm{pH}$ próximos a 8,7. Por isso, optou-se por avaliar a viabilidade das sementes em função da coloração da solução de embebição associada ao aspecto dos tecidos. Dessa forma foi possível identificar 71\% e $66 \%$ de sementes viáveis após 4 e 8 dias de envelhecimento artificial, respectivamente (Tabela 2).

Relacionando os resultados obtidos pelo teste do $\mathrm{pH}$ do exsudato aos demais testes de viabilidade, observou-se que o maior percentual de viabilidade encontrado apresentou coeficiente de correlação significativo com o percentual obtido pelo teste de germinação para o lote $1(r=0,58)$, lote $2(r=0,90)$, para sementes envelhecidas por 4 dias $(r=0,75)$ e 8 dias $(\mathrm{r}=0,46)$. O percentual de viabilidade obtido pelo $\mathrm{pH}$ do exsudato também apresentou coeficiente de correlação significativo com o percentual obtido pelo tetrazólio para o lote $1(\mathrm{r}=0,82)$, lote $2(0,85)$, sementes envelhecidas por 4 dias $(r=0,58)$ e 8 dias $(r=0,45)$.

Analisando-se os resultados através de uma regressão linear simples, constatou-se que $84 \%$ e 92\% dos resultados de germinação e tetrazólio,

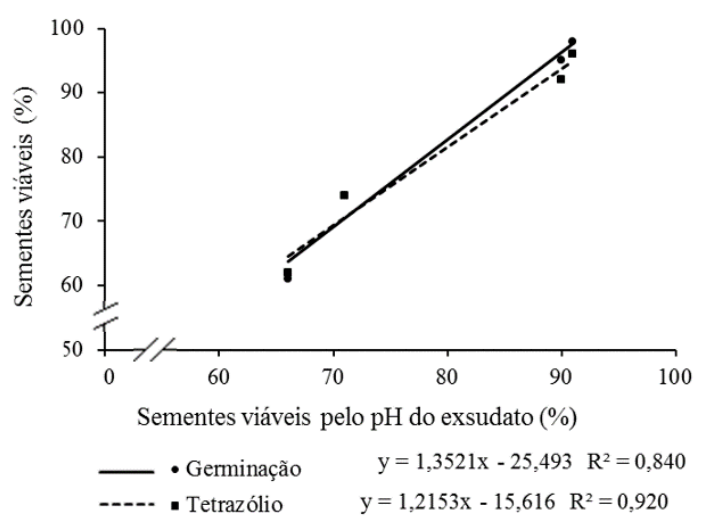

Figura 1. Relação entre o teste do $\mathrm{pH}$ do exsudato realizado em embriões excisados de sementes de A. angustifolia e embebidos em água por 30 minutos, antes e após o envelhecimento artificial por 4 e 8 dias, com a viabilidade observada pelos testes de germinação e tetrazólio.

Figure 1. Relation between $\mathrm{pH}$ exudate test performed in excised embryos from A. angustifolia seeds and imbibed in water for 30 minutes, before and after artificial aging for four and eight days, with the viability observed by germination and tetrazolium tests. respectivamente, podem ser explicados pelas equações em função dos resultados de $\mathrm{pH}$ do exsudato, as quais estão representadas na Figura 1. Esses percentuais podem ser considerados elevados considerando-se que as amostras de trabalho utilizadas para o $\mathrm{pH}$ do exsudato não podem ser reaproveitadas para o teste de germinação mas apenas para o tetrazólio.

Sabe-se que o desenvolvimento de uma metodologia para o teste do $\mathrm{pH}$ do exsudato em sementes deve ser realizado com forte embasamento científico por parte dos pesquisadores, buscando adequá-la às condições intrínsecas à espécie. Os resultados observados indicam que o teste do $\mathrm{pH}$ do exsudato pode ser eficiente para avaliar a viabilidade de sementes de A. angustifolia, garantindo o estabelecimento inicial das plântulas com base na identificação de embriões viáveis e fornecendo informações importantes para a tomada de decisões sobre a melhor forma de aproveitamento dos lotes de sementes. No entanto, para a avaliação de sementes em avançado processo de deterioração torna-se necessário que o avaliador do teste possua conhecimento técnico-científico específico para identificar as estruturas essenciais ao crescimento do eixo embrionário durante a formação de plântulas normais, proporcionando a correta análise sobre o aspecto dos tecidos, levando em consideração a extensão, a coloração, a consistência e a localização dos possíveis danos, associando tais aspectos à coloração da solução de embebição.

\section{CONCLUSÃO}

Conclui-se que o teste do $\mathrm{pH}$ do exsudato é eficiente para estimar de forma rápida a viabilidade de sementes de Araucaria angustifolia, devendo ser realizado em embriões excisados e embebidos em água destilada pelo período de 30 minutos.

O teste de $\mathrm{pH}$ do exsudato é eficiente para se determinar a viabilidade de sementes em avançado estádio de deterioração, desde que seja considerada a integridade dos tecidos.

\section{AGRADECIMENTOS}

O primeiro autor agradece à Fundação de Amparo à Pesquisa e Inovação do Estado de Santa Catarina (Fapesc) pela bolsa de doutorado concedida. 
O segundo autor agradece ao Conselho Nacional de Desenvolvimento Científico e Tecnológico (CNPq) pela bolsa de produtividade concedida.

\section{STATUS DA SUBMISSÃO}

Recebido: 13 mar., 2014

Aceito: 21 abr., 2015

\section{AUTOR(ES) PARA CORRESPONDÊNCIA}

\section{Cileide Maria Medeiros Coelho}

Departamento de Agronomia, Centro de Ciências Agrárias, Universidade do Estado de Santa Catarina - UDESC, Av. Luiz de Camões, 2090, Conta Dinheiro, CEP 88520-000, Lages, SC, Brasil e-mail: cileidecoelho@yahoo.com.br

\section{APOIO FINANCEIRO}

Fundação de Amparo à Pesquisa e Inovação do Estado de Santa Catarina (FAPESC) e Conselho Nacional de Desenvolvimento Científico e Tecnológico (CNPq).

\section{REFERENNCIAS}

Amaral AS, Peske ST. pH do exsudato para estimar, em 30 minutos, a viabilidade de sementes de soja. Revista Brasileira de Sementes 1984; 6(3): 85-92.

Amaral AS, Peske ST. Testes para avaliação rápida da qualidade fisiológica de sementes de trigo. Revista Brasileira de Agrociência 2000; 6(1): 12-15.

Balbuena TS, Jo L, Pieruzzi FP, Dias LLC, Silveira V, Santa-Catarina C et al. Differential proteome analysis of mature and germinated embryos of Araucaria angustifolia. Phytochemistry 2011; 72(4-5): 302-311. http://dx.doi. org/10.1016/j.phytochem.2010.12.007. PMid:21276992.

Barbieri APP, Menezes NL, Conceição GM, Tunes LM. Teste de lixiviação de potássio para a avaliação do vigor de sementes de arroz. Revista Brasileira de Sementes 2012; 34(1): 117-124. http://dx.doi.org/10.1590/S010131222012000100015 .

Brasil. Ministério da Agricultura, Pecuária e Abastecimento MAPA. Regras para análise de sementes. Brasília: ACS; 2009.

Cabrera AC, Peske ST. Testes do pH do exsudato para sementes de milho. Revista Brasileira de Sementes 2002; 24(1): 134-140.

Carvalho JA, Von Pinho EVR, Oliveira JA, Guimarães RM, Bonome LT. Testes rápidos para avaliação da qualidade fisiológica de sementes de Citromelo swingle. Revista Brasileira de Sementes 2002; 24(1): 263-270.

Fernandes EJ, Sader RJ, Carvalho NM. Viabilidade de sementes de feijão (Phaseolus vulgaris L.) estimada pelo $\mathrm{pH}$ do exsudato. Revista Brasileira de Sementes 1987; 9(3): 69-75.

Fontes BPD, Davide LC, Davide AC. Fisiologia e citogenética de sementes envelhecidas de Araucaria angustifolia. Ciência e Agrotecnologia 2001; 25(2): 346-355.

Garcia C, Coelho CMM, Maraschin M, Oliveira LM. Conservação da viabilidade e vigor de sementes de Araucaria angustifolia (Bert.) O. Kuntze durante o armazenamento. Ciência Florestal 2014; 24(4): 857-866. http://dx.doi.org/10.5902/1980509816586.

Hilst PC, Dias DCFS, Alvarenga EM, Souza BL. Test of exudates color hues for evaluating the physiological potential of coffee (Coffea arabica L.) seeds. Revista Brasileira de Sementes 2012; 34(2): 212-217. http://dx.doi. org/10.1590/S0101-31222012000200004.

Krzyzanowski FC, Vieira RD, França Neto JB. Vigor de Sementes: conceitos e testes. Londrina: Associação Brasileira de Tecnologia de Sementes; 1999.

Lopes MM, Silva CB, Vieira RD. Physiological potential of eggplant seeds. Journal of Seed Science 2013; 35(2): 225-230. http://dx.doi.org/10.1590/S2317-15372013000200012.

Maguire JD. Speed of germination-aid in selection and evaluation for seedling emergence and vigour. Crop Science 1962; 2(2): 176-177. http://dx.doi.org/10.2135/cropsci19 62.0011183X000200020033x

Matos JMM, Martins RCC, Martins IS. Caracterização do teste de $\mathrm{pH}$ de exsudato pelo método individual para avaliação da viabilidade de sementes de Copaifera langsdorffi Desf. Revista Heringeriana 2009; 3: 81-87.

Medeiros ACS, Abreu DCA. Desidratação ultra-rápida de embriões. Pesquisa Florestal Brasileira 2007; 54: 119-125.

Moreira-Souza M, Cardoso EJBN. Practical method for germination of Araucaria angustifolia (Bert.) O. Ktze. seeds. Scientia Agricola 2003; 60(2): 389-391. http://dx.doi. org/10.1590/S0103-90162003000200025.

Muasya RM, Lommen WJM, Auma EO, Struik PC. Relationship between variation in quality of individual seeds and bulk seed quality in common bean (Phaseolus vulgaris L.) seed lots. Wageningem Journal of Life Sciences 2006; 54(1): 5-16. http://dx.doi.org/10.1016/S15735214(06)80001-1.

Oliveira LM, Gomes JP, Souza GK, Nicoletti MF, Liz TO, Pikart TG. Metodologia alternativa para o teste de tetrazólio em sementes de Araucaria angustifolia (Bertol.) Kuntze. Floresta e Ambiente 2014; 21(4): 468-474. http:// dx.doi.org/10.1590/2179-8087.064413.

Ramos KMO, Matos JMM, Martins RCC, Martins IS. Electrical conductivity testing as applied to the assessment 
of freshly. ISRN Agronomy 2012; 2012: 1-5. http://dx.doi. org/10.5402/2012/378139.

Rech EG, Villela FA, Tillmann MA. Avaliação rápida da qualidade fisiológica de sementes de ervilha. Revista Brasileira de Sementes 1999; 21(2): 1-9.

Reis LS, Araújo EF, Dias DCFS, Sediyama CS, Meireles RC. LERCAFÉ: novo teste para estimar o potencial germinativo de sementes de cafeeiro (Coffea arabica L.). Revista Brasileira de Sementes 2010; 32(1): 9-16.

Santos JF, Alvarenga RO, Timóteo TS, Conforto EC, Marcos Filho J, Vieira RD. Avaliação do potencial fisiológico de lotes de sementes de soja. Revista Brasileira de Sementes 2011; 33(4): 743-751. http://dx.doi.org/10.1590/S010131222011000400016 .
Statistical Analisys System Institute - SAS. SAS Institute $I n c^{\circledast}$ 2009. Version 9.2. Cary; 2009.

Schlögl PS, Souza AP, Nodari RO. PCR-RFLP analysis of non-coding regions of cpDNA in Araucaria angustifolia (Bert.) O. Kuntze. Genetics and Molecular Biology 2007; 30(2): 423-427. http://dx.doi.org/10.1590/S141547572007000300020 .

Shibata M, Coelho CMM, Steiner N. Physiological quality of Araucaria angustifolia seeds at different stages of development. Seed Science and Technology 2013; 41(2): 214-224. http://dx.doi.org/10.15258/sst.2013.41.2.04.

Tozzo GA, Peske ST. Qualidade fisiológica de sementes de soja comerciais e de sementes salvas. Revista Brasileira de Sementes 2008; 30(2): 12-18. http://dx.doi.org/10.1590/ S0101-31222008000200002. 